\title{
Endoscopic ultrasound-guided jejunojejunal anastomosis as salvage therapy for a complex gastric outlet obstruction
}

Lumen-apposing metal stents are gaining ground in the treatment of gastric outlet obstruction (GOO) caused by malignant duodenal stenosis [1]. This technique is also opening up new alternatives as a rescue therapy for patients presenting with benign $\mathrm{GOO}$ and a previous history of gastric surgery or endoscopic procedures [2].

A 76-year-old man with recurrent colorectal cancer presented with GOO due to a metastatic lymph node in the distal duodenum. A surgical gastrojejunostomy was performed. The patient presented again with GOO 1 month later and a nasogastric tube was placed, producing 1-2 L/day. Computed tomography confirmed the absence of contrast opacification of the alimentary limb, with all the contrast accumulating in the afferent loop. Upper gastrointestinal endoscopy revealed kinking of the proximal efferent limb, resulting in a very narrow passage and a $7-\mathrm{cm}$ complex stricture of the proximal lumen.

First, a deep canulation of the alimentary jejunal limb was performed with placement of a wire-guided 7-French catheter distal to the mechanical jejunal stricture. The catheter was left in place through the mouth and connected to a water pump. Then, an endoscopic ultrasound (EUS) scope was advanced gently into the afferent limb at $10 \mathrm{~cm}$ distance from the surgical gastrojejunostomy ( $\triangleright$ Video 1 ). The catheter was necessary to identify the right limb by EUS and dilate the bowels ( $\mathbf{F i g}$. 1).As dilation of the efferent limb was not possible, a hybrid technique was decided on as follows. The efferent limb was punctured with a 19-gauge needle (Expect; Boston Scientific) and a 0.035 -in. guidewire was advanced. Finally, a 20-mm lumen-apposing metal stent (HotAxios; Boston Scientific) was used to perform the jejunojejunal anastomo-

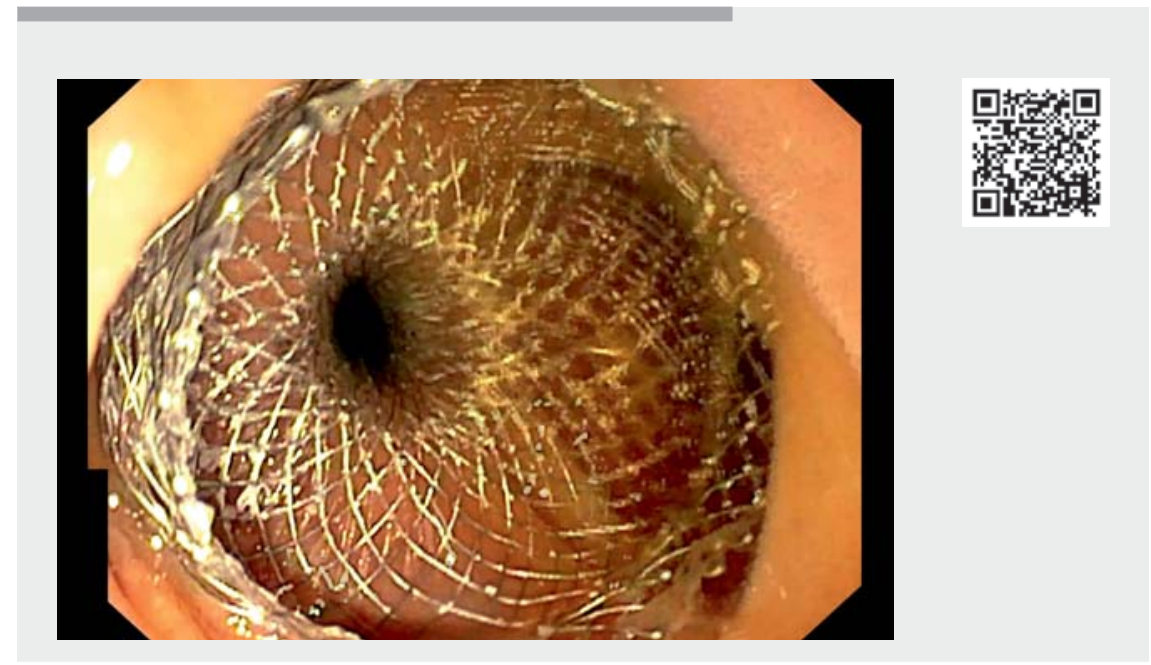

Video 1 Endoscopic ultrasound-guided jejunojejunal anastomosis in a patient with a past history of gastric surgery who presented with gastric outlet obstruction.

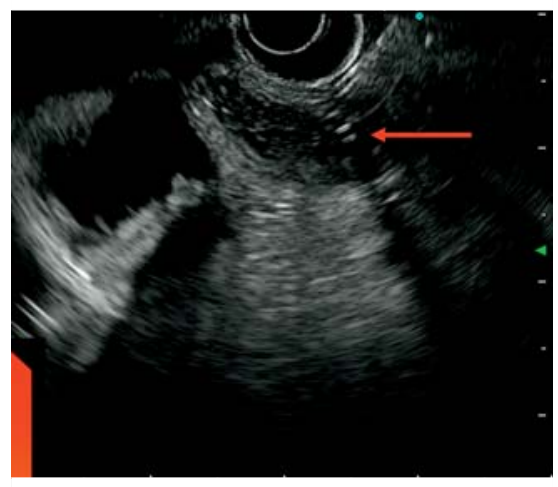

- Fig. 1 Endoscopic ultrasound visualization of the alimentary limb with a 7-French cannula in place (red arrow).

sis using autocut monopolar current ( $>$ Fig. 2). The patient recovered well and started liquid oral intake the day after with solid diet $48 \mathrm{~h}$ later. No delayed complications were reported. The patient died 1 month later from other causes.

Endoscopy_UCTN_Code_TTT_1AO_2AZ

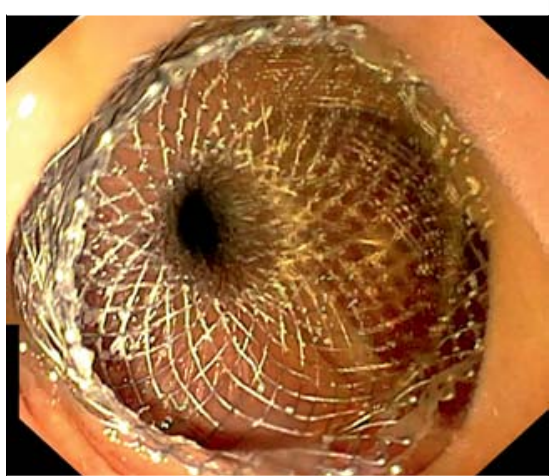

- Fig. 2 Endoscopic view of a 20-mm lumen-apposing metal stent. Jejunojejunal anastomosis.

Competing interests

Enrique Pérez-Cuadrado-Robles is a consultant for Boston Scientific. The other authors have no conflict of interest relating to this article. 
The authors

Enrique Pérez-Cuadrado-Robles ${ }^{1}$, Guillaume Perrod $^{1}{ }^{\circ}$, Alexandre Lansier ${ }^{2}$, Juliette Palle ${ }^{3}$, Antoine Mariani ${ }^{4}$, Christophe Cellier ${ }^{1}$, Gabriel Rahmi $^{1}$

1 Department of Gastroenterology, GeorgesPompidou European Hospital, Paris, France

2 Department of Radiology, GeorgesPompidou European Hospital, Paris, France

3 Department of Oncology, GeorgesPompidou European Hospital, Paris, France

4 Department of Surgery, Georges-Pompidou European Hospital, Paris, France

Corresponding author

Enrique Pérez-Cuadrado-Robles, MD, PhD Department of Gastroenterology, GeorgesPompidou European Hospital, 20 Rue Leblanc, 75015 Paris, France

kikemurcia@gmail.com

\section{References}

[1] Ahmed O, Lee JH, Thompson CC et al. AGA clinical practice update on the optimal management of the malignant alimentary tract obstruction: expert review. Clin Gastroenterol Hepatol 2021; 19: 1780-1788

[2] Pérez-Cuadrado-Robles E, Perrod G, Benosman $\mathrm{H}$ et al. Endoscopic ultrasound-guided gastrojejunostomy as a rescue therapy for gastric outlet obstruction in a patient with multiple previous procedures. Endoscopy 2021; 53: E143-E144

Bibliography

Endoscopy 2022; 54: E633-E634

DOI $10.1055 / \mathrm{a}-1730-4200$

ISSN 0013-726X

published online 4.2.2022

(C) 2022. Thieme. All rights reserved.

Georg Thieme Verlag KG, Rüdigerstraße 14

70469 Stuttgart, Germany
ENDOSCOPY E-VIDEOS

https://eref.thieme.de/e-videos

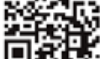
Endoscopy E-Videos is an open access online section, reporting on interesting cases and new techniques in gastroenterological endoscopy. All papers include a high quality video and all contributions are freely accessible online. Processing charges apply (currently EUR 375), discounts and wavers acc. to HINARI are available.

This section has its own submission website at

https://mc.manuscriptcentral.com/e-videos 